\title{
Safety and Immunogenicity of Cuban Antipneumococcal Conjugate Vaccine PCV7-TT in Healthy Adults
}

\author{
Nadezhda González MD MS, Beatriz Paredes, Sonia Pérez MD, Mayelín Mirabal MS, Ivonne Rivero, \\ Carlos A. González MD MS, Alina Díaz MD, Dagmar García PhD, Laura Rodríguez, Amarilis Pérez, Yamilka Soroa DVM, \\ Darielis Santana, Alina Álvarez MD, Yury Valdés, Vicente Vérez PhD
}

\begin{abstract}
INTRODUCTION Pneumococcal infections are a major cause of morbidity and mortality and are associated with considerable economic burden on health systems. To prevent pneumococcal infections, 7-valent conjugate vaccines have been available for over a decade; more recently, 10 - and 13-valent conjugate vaccines have been formulated, which are more immunogenic than vaccines with capsular polysaccharides only. In Cuba, a new vaccine candidate has been developed, PCV7-TT, a conjugate of tetanus toxoid with antigens of seven of the serotypes of Streptococcus pneumoniae with highest circulation in Cuba and in the world: 1, 5, 6B, 14, 18C, $19 \mathrm{~F}$ and $23 \mathrm{~F}$
\end{abstract}

OBJECTIVE Assess the safety of the vaccine candidate PCV7-TT in healthy adults and conduct a preliminary assessment of its immunogenicity.

METHODS A phase I, double-blind clinical trial was performed at the National Toxicology Center in Havana, Cuba. Healthy male volunteers aged 18-35 years were randomly assigned to two groups: 20 received the vaccine candidate PCV7-TT and 20 the polyvalent antipneumococcal vaccine PNEUMO-23 used as control, each in a single intramuscular dose. To assess safety, the occurrence of adverse events was monitored for 30 days following inoculation. To explore immunogenicity, concentrations of serotype-specific antibodies was quantified before and 30 days after inoculation, as well titers of opsonophagocytic antibodies. (National Clinical Trial Registry RPCEC00000133)
RESULTS Local adverse events were pain, redness, induration, increased sensitivity to touch, and warmth in the injection area. Pain was registered in $70 \%$ of individuals who received PCV7-TT and in $75 \%$ of those vaccinated with PNEUMO-23. Reported systemic adverse events were general malaise, headache and drowsiness. All adverse events appeared in the first 72 hours post inoculation and lasted no longer than 3 days. One event was reported that was classified as severe in intensity and serious in consequences, but it was unrelated to vaccination-acute appendicitis in one individual inoculated with the control vaccine. Before vaccination, all participants but one had antibody concentrations $\geq 0.20 \mu \mathrm{g} / \mathrm{ml}$ against the vaccine strains; after vaccination $100 \%$ of individuals were positive and the concentrations of antibodies increased in previously positive volunteers. Some individuals had opsonophagocytic antibodies against serotypes $1,14,19 \mathrm{~F}$ and $23 \mathrm{~F}$ before vaccination, with highest concentrations against serotypes 14 and $19 \mathrm{~F}$. After vaccination, the percent of individuals with opsonophagocytic titers $\geq 1: 8$ for all serotypes in the vaccine was $>50 \%$ in both groups.

CONCLUSIONS A single dose of candidate vaccine PCV7-TT was safe when used in healthy adults. Preliminary results showed that it was able to activate an immune response against the serotypes of Streptococcus pneumoniae used.

KEYWORDS Invasive pneumococcal diseases, pneumococcal vaccines, conjugate vaccines, immunization, randomized clinical trial, safety, Cuba

\section{INTRODUCTION}

Infections by Streptococcus pneumoniae or pneumococcus are among the main vaccine-preventable diseases. They are considered a major public health problem worldwide and impose a substantial economic burden on health systems. [1-3] WHO estimates that pneumococcal infections kill some 100,000 children aged $<5$ years every year, most in developing countries. $[4,5]$

Clinical infections by pneumococcus are usually called pneumococcal diseases. If the infection is associated with bacteremia, pneumonia or meningitis, they are described as invasive pneumococcal diseases (IPD); [6,7] noninvasive pneumococcal diseases may include sinusitis, bronchitis or middle ear infections.[8]

Epidemiological studies of pneumococcus are complex since over 90 serotypes have been identified, as determined by capsular polysaccharides.[3,9] It has been shown, however, that the serotypes most frequently associated with higher incidence of IPD in children aged $<5$ years worldwide are: $1,5,6 \mathrm{~A}, 6 \mathrm{~B}, 14$, $19 F$ and 23F.[10] Serotype 14 is the most common globally and is associated with $12 \%-29 \%$ of all IPD. Serotype $6 \mathrm{~B}$ is the second most common for all regions except Africa; serotypes $6 \mathrm{~A}$ and $6 \mathrm{~B}$ combined are associated with $14 \%-18 \%$ of all IPD. Serotypes 1 , 5 and 14 are found in $28 \%-43 \%$ of all IPD worldwide; therefore,
WHO recommends inclusion of these three serotypes in all new pneumococcal vaccines.[11]

Cuban epidemiological studies of pneumococcal diseases during the past decade are sparse in relation to the number of isolates. Between 2000 and 2005, a total of 1332 isolates were obtained at Cuba's Pedro Kourí Tropical Medicine Institute (IPK). Most were from children aged $<6$ years (842 cases) and adults aged $>60$ years (302 cases). Although the number of isolates and serotype identifications was low, it was concluded that serotypes 1, 6B, $14,18 \mathrm{C}, 19 \mathrm{~F}$ and 23F predominate in Cuba.[12] In the last few years, such serotypes as 3, 4, 7F, 9V, 15 and 19A have also been reported.[13] Another IPK study in 2010 evaluated the behavior of bacterial meningitis by Streptococcus pneumoniae, finding that serotypes $6 \mathrm{~A}, 6 \mathrm{~B}, 14$ and $23 \mathrm{~F}$ are still the most frequent serotypes in Cuba.[14]

The first conjugate vaccine against Streptococcus pneumoniae, Prevnar-7, appeared on the market in the year 2000; it was more immunogenic than vaccines that included only capsular polysaccharides. Prevnar-7 protected against serotypes 4, 6B, 9V, 14, $18 \mathrm{C}, 19 \mathrm{~F}$ and $23 \mathrm{~F}$. Using this formulation as a reference, two other conjugate vaccines were licensed in 2010: Synflorix that included also serotypes 1, 5 and $7 \mathrm{~F}$ and Prevnar 13, with the addition of 1 , $3,5,6 \mathrm{~A}, 7 \mathrm{~F}$ and 19A.[15] 
Beginning in 2008, Cuba's Biomolecular Chemistry Center (CQB) developed PCV7-TT, a new conjugate antipneumococcal vaccine candidate, following WHO's recommendations (Target Product Profile and Advance Market Commitment) for conjugate antipneumococcal vaccines, as well as reports from PAHO's Surveillance System for the Bacterial Agents Responsible for Pneumonia and Meningitis Network.[16,17] This vaccine is formulated with antigens of seven of the most frequent serotypes circulating in Cuba and worldwide $(1,5,6 \mathrm{~B}, 14,18 \mathrm{C}, 19 \mathrm{~F}$ and $23 \mathrm{~F})$, conjugated to tetanus toxoid.

The vaccine candidate PCV7-TT is intended for use in infants; however, before using it in this age group it was decided to vaccinate young adults, even though they are not the target population for antipneumococcal vaccines. This design was motivated by the same ethical considerations already followed in similar research: to protect the most vulnerable population,[18] in this case by demonstrating the safety of a product in an adult population before testing it in children.

The study's objectives were to evaluate the safety in healthy adults of the vaccine candidate PCV7-TT, a conjugate heptavalent vaccine against pneumococcus, and to conduct a preliminary assessment of its immunogenicity.

\section{METHODS}

Study design A parallel, double-blind, controlled, randomized phase I clinical trial was performed between June 17 and July 30, 2012, at the National Toxicology Center (CENATOX), Havana, Cuba. CENATOX specializes in and has been certified to conduct this type of clinical study.

Inclusion criteria From 79 male Havana residents 18-35 years old who signed the study consent form, 40 participants were selected based on these criteria: age 18-35 years with normal physical exams (general, regional and functional), vital signs within normal limits, body mass index $18.5-29.9 \mathrm{~kg} / \mathrm{m}^{2}$, hemoglobin values higher than $12.5 \mathrm{~g} / \mathrm{L}$, and other laboratory test results within reference values: hematologic (hematocrit, erythrocyte sedimentation rate and leukocyte differential), blood chemistry (glucose, creatinine, total bilirubin and transaminases), urine, and microbiologic (VIH, HBsAg, VDRL serology and hepatitis C antibodies).

Exclusion criteria Chronic diseases; congenital and acquired immunodeficiencies; severe allergies, hypersensitivity to thiomersal or to another compound in the vaccine; psychiatric or neurologic disorders that hinder free consent and/or followup; alcoholism; convulsive encephalopathy; fever or any acute infection within 10 days before vaccination or at the time of vaccination; previous treatment (within 2 months) with immunosuppressants or immunostimulants or with products derived from blood, or immunization with another vaccine; and previous immunization against Streptococcus pneumoniae.

Withdrawal criteria Voluntary withdrawal; appearance of exclusion criteria or serious adverse event; application of another vaccine, immunoglobulin, experimental medication or blood derivatives.

Ethics This study was performed in accordance with the Ethical Principles for Medical Research Involving Human Subjects, as established in the Helsinki Declaration[19] and Cuban standards of good clinical practice.[20] It is listed in the National Clinical Trial Registry with code RPCEC00000133. The CENATOX ethics committee approved the design, and the Government Center for Quality Control of Medicines authorized the clinical trial. Written informed consent was obtained from all participants.

Treatment Participants were randomly assigned to 2 treatment groups: 20 subjects were inoculated with PCV7-TT, and 20 received the polyvalent antipneumococcal vaccine PNEUMO-23 (Sanofi Pasteur, S.A. France). All volunteers received a single 0.5 $\mathrm{mL}$ dose intramuscularly in the deltoid region.

A random list was generated using a scheme of blocks of 4 (rate $1: 1)$ obtained from a program routine using $S$ language, $R$ implementation, 2.11.0 version for Windows. The list was stored at the CQB's Quality Control Office.

The vaccine candidate PCV7-TT includes $2 \mu \mathrm{g}$ of serotypes 1,5 , $14,18 \mathrm{C}, 19 \mathrm{~F}$ and $23 \mathrm{~F}$, plus $4 \mu \mathrm{g}$ of $6 \mathrm{~B}$, each serotype conjugated to tetanus toxoid (TT), with a total of $24.5 \mu \mathrm{g}$ of TT in the formulation, plus $125 \mu \mathrm{g}$ of aluminum phosphate as adjuvant and 0.058 $\mu \mathrm{g}$ of thiomersal. It is provided as a single-use $0.7-\mathrm{mL}$ ampoule for $0.5 \mathrm{~mL}$ for vaccination. The PCV7-TT batch used was NEU.12.01, with expiry date August 15, 2012.

The polyvalent anti pneumococcal vaccine PNEUMO-23, used as a control, is a preparation of purified capsule polysaccharides from 23 serotypes of Streptococcus pneumoniae. Each $0.5 \mathrm{ml}$ dose contains: $25 \mu \mathrm{g}$ of capsular polysaccharide of each of serotypes 1, 2, 3, 4, 5, 6B, 7F, 8, 9N, 9V, 10A, 11A, 12F, 14, 15B, $17 \mathrm{~F}, 18 \mathrm{C}, 19 \mathrm{~A}, 19 \mathrm{~F}, 20,22 \mathrm{~F}, 23 \mathrm{~F}$ and $33 \mathrm{~F}$. It is provided as a small glass syringe preloaded with a $0.5 \mathrm{ml}$ dose. Expiration date of the PNEUMO-23 batch used, G0512-5, was September 2012. PNEUMO-23 was selected as control following analysis of its previous use in studies of safety in adults. It has been used in clinical assays of safety for other commercial vaccines such as Prevnar 7 and Prevnar 13, as well as for an unlicensed 11-valent Aventis vaccine. All these studies compared the new products with the polysaccharide 23-valent vaccine.[21-24]

Because the vaccines differ in appearance, blinding was achieved by physical barriers between participants and nurses who prepared and inoculated the participants. This was done using a door with a shoulder-height opening through which participants' arms could be introduced for inoculation.

Safety Participants were monitored for adverse effects for 30 days post immunization; each subject logged all adverse effects appearing during this period. Volunteers were under strict medical supervision through three hours post vaccination, with active monitoring for appearance of immediate adverse effects. Subsequently, they moved into ambulatory followup with medical assessment in clinics at 24, 48 and 72 hours post immunization, as well as at 7, 21 and 30 days. An algorithm that classifies adverse effects as related and unrelated to vaccination (proposed by Havana's Finlay Institute) was used to assess a causal relationship between an adverse effect and the vaccine.[25] Adverse effects were also classified as mild, moderate or severe in intensity and as serious or not serious in terms of health consequences.[26] 
Immunogenicity Two blood samples were taken, one immediately before vaccination (TO) and one 30 days post vaccination (T30). Concentration of anticapsular antibodies was determined by ELISA for the seven serotypes included in the candidate PCV7-TT vaccine, by double absorption using $\mathrm{C}$ and 22F polysaccharides, as optimized and validated by the CQB immunology laboratory, in accordance with WHO's protocol.[27,28] The titer of opsonophagocytic antibodies (OPA) was determined by an assay, counting viability and using neutrophils from donors as effectors; this was also optimized and validated by the CQB immunology laboratory. WHO's general protocol for OPA assay was used, except that neutrophils were used instead of HL-60 cells. The OPA titer was expressed as the reciprocal of the serum dilution that reduced colony-forming units by $50 \%$, compared with a control without human serum.[27]

Analysis Sample sizes of 20 in each group provided $>95 \%$ probability of detecting adverse effects occurring in $>10 \%$ of subjects. Statistical analysis was performed with $\mathrm{S}$ language, $\mathrm{R}$ implementation, version 2.11.0 for Windows. For all comparisons, a significance level of $5 \%$ was used. The SQL format database used was prepared by the CQB's data management group. All data were digitized and cleaned.

Safety and reactogenicity data were presented as incidence and intensity of adverse events reported after vaccination. For individuals who reported adverse events, general and study-group incidences were tabulated as percent of events in the 30 days following vaccine administration. The proportion of subjects with at least one expected adverse event (local or systemic) during the first seven days of followup was calculated for both intervention groups, independent of their intensity, and the proportion of subjects with at least one unexpected event during the whole followup period was calculated as well. Adverse events were classified by their intensity and relation with the vaccine. In addition, incidence of serious adverse events at any moment during the study was determined, event association with the vaccine assessed, and the result of each event described.

To analyze immunogenicity, geometric mean concentration of antibodies against each serotype and $95 \% \mathrm{Cl}$ were calculated for each study group. For both study groups, percent of seroprotected individuals with OPA titers $\geq 1: 8$ for each vaccine serotype, and percent of seroprotected individuals with concentrations of serotype-specific IgG antibodies $\geq 0.20 \mu \mathrm{g} / \mathrm{mL}$ were calculated before and after vaccination. Confidence intervals $(95 \%)$ were calculated for the difference between percent of volunteers in each study group who reached IgG concentrations $\geq 0.20 \mu \mathrm{g} / \mathrm{mL}$ and/or OPA titers $\geq 1.8$ at 30 days post vaccination.

\section{RESULTS}

Participant assessment and recruitment Main causes for exclusion were chronic diseases and hemoglobin concentrations lower than $12.5 \mathrm{~g} / \mathrm{L}$ or other abnormal laboratory parameters. One subject in the PCV7-TT group abandoned the study after checkout at day seven, so was included in safety analysis but not immunogenicity.

Safety A total of 50 adverse events, 28 assessed as vaccine related, were reported by individuals who received the PCV7-TT vaccine candidate. Those vaccinated with PNEUMO-23 reported 44 adverse events, 28 assessed as vaccine related. All vaccinerelated adverse events appeared in the first 72 hours after immunization and lasted $\leq 3$ days. Similar results were obtained for both groups (Table 1).

\begin{tabular}{|c|c|c|c|c|c|}
\hline \multirow{2}{*}{\multicolumn{2}{|c|}{ Adverse event }} & \multicolumn{2}{|c|}{ PCV7-TT } & \multicolumn{2}{|c|}{ PNEUMO-23 } \\
\hline & & \multirow{2}{*}{\begin{tabular}{r|}
$n$ \\
14
\end{tabular}} & \multirow{2}{*}{$\begin{array}{r}\% \\
70\end{array}$} & \multirow{2}{*}{$\begin{array}{r}\mathrm{n} \\
15\end{array}$} & \multirow{2}{*}{$\begin{array}{r}\% \\
75\end{array}$} \\
\hline Local & Pain & & & & \\
\hline & $\begin{array}{l}\text { Temperature increase at } \\
\text { inoculation site }\end{array}$ & 5 & 25 & 4 & 20 \\
\hline & Reddening & 4 & 20 & 4 & 20 \\
\hline & Induration & 2 & 10 & 1 & 5 \\
\hline & $\begin{array}{l}\text { Swelling in vaccinated } \\
\text { arm }\end{array}$ & 1 & 5 & 1 & 5 \\
\hline & $\begin{array}{l}\text { Hypersensitivity to touch } \\
\text { in vaccinated arm }\end{array}$ & 0 & 0 & 1 & 5 \\
\hline \multirow[t]{3}{*}{ Systemic } & Malaise & 1 & 5 & 1 & 5 \\
\hline & Headache & 0 & 0 & 1 & 5 \\
\hline & Drowsiness & 1 & 5 & 0 & 0 \\
\hline
\end{tabular}

Local vaccine-related adverse events (26 in each group) appeared in 16 volunteers (80\%) vaccinated with PCV7-TT and in 15 (75\%) receiving PNEUMO-23. Reported local events for both groups, in order of frequency, were: pain, increase in local temperature, reddening, induration, swelling and hypersensitivity to touch of the vaccinated arm (Table 1).

Systemic vaccine-related adverse events were reported in 2 subjects $(10 \%)$ receiving PCV7-TT and 2 subjects $(10 \%)$ receiving the control vaccine. Systemic adverse events were general malaise, headache and drowsiness (Table 1). Only one severe adverse event was reported during the study period, acute appendicitis in a volunteer immunized with PNEUMO-23.

Other adverse events seen during the study were not attributable to vaccination. A total of 22 events were reported in the PCV7-TT group and 16 after vaccination with PNEUMO-23. Some of these events were the same for both vaccines: hypertension (two subjects in each group), respiratory infection (4 subjects with PCV7-TT and 2 subjects with PNEUMO-23) and diarrhea (2 subjects with PCV7-TT and 1 with PNEUMO-23). Other events seen in subjects inoculated with PCV7-TT were vomiting in 1 subject, headache (2), aphthous ulcers (2); 1 participant suffered a leg trauma and 10 presented abnormal but clinically insignificant laboratory results. Additional adverse events reported in the group immunized with PNEUMO-23 were: allergic rhinitis (2 subjects), acute pharyngitis (1), arthralgia (2); 1 subject had an acute appendicitis episode, and 3 showed laboratory values outside normal ranges but clinically nonsignificant.

Immunogenicity Before vaccination, all but one participant had basal concentrations of antibodies $\geq 0.20 \mu \mathrm{g} / \mathrm{mL}$ against each of the serotypes analyzed. After a single dose of PCV7-TT or of PNEUMO-23, the concentration of antibodies increased significantly in both groups $(p \leq 0.05)$ (Table 2$)$.

Before vaccination, some volunteers in both groups already had OPA titers $\geq 1.8$ against serotypes 1 (5\% in PCV7-TT group and 
Table 2: IgG antibodies against S. pneumoniae polysaccharides, ELISA

\begin{tabular}{|c|c|c|c|c|c|c|c|c|}
\hline \multirow{4}{*}{ Serotype } & \multicolumn{8}{|c|}{$\lg G(\mu \mathrm{g} / \mathrm{ml})$} \\
\hline & \multicolumn{4}{|c|}{ PCV7-TT } & \multicolumn{4}{|c|}{ PNEUMO-23 } \\
\hline & \multicolumn{2}{|c|}{$\begin{array}{l}\text { Pre vaccination } \\
\qquad(n=20)\end{array}$} & \multicolumn{2}{|c|}{$\begin{array}{l}\text { Post vaccination } \\
\qquad(n=19)\end{array}$} & \multicolumn{2}{|c|}{$\begin{array}{l}\text { Pre vaccination } \\
(n=20)\end{array}$} & \multicolumn{2}{|c|}{$\begin{array}{l}\text { Post vaccination } \\
\qquad(n=20)\end{array}$} \\
\hline & GMC & $(95 \% \mathrm{CI})$ & GMC & $(95 \% \mathrm{CI})$ & GMC & $(95 \% \mathrm{Cl})$ & GMC & $(95 \% \mathrm{Cl})$ \\
\hline 1 & 1.48 & $0.96-2.28$ & 4.61 & $3.17-6.68$ & 1.51 & $0.91-2.51$ & 9.03 & $5.77-14.13$ \\
\hline 5 & 2.89 & $2.13-3.90$ & 4.48 & $3.23-6.22$ & 2.40 & $1.79-3.21$ & 7.00 & $5.11-9.60$ \\
\hline $6 B$ & 2.67 & $1.98-3.60$ & 4.33 & $3.06-6.12$ & 2.15 & $1.65-2.81$ & 5.56 & $3.56-8.70$ \\
\hline 14 & 9.87 & $7.13-13.67$ & 32.90 & $19.97-54.19$ & 10.03 & $8.22-12.24$ & 25.51 & $19.06-34.15$ \\
\hline $18 \mathrm{C}$ & 2.21 & $1.53-3.18$ & 3.25 & $2.13-4.97$ & 2.20 & $1.61-3.00$ & 6.17 & $4.15-9.18$ \\
\hline $19 \mathrm{~F}$ & 4.38 & $3.31-5.79$ & 6.06 & $4.15-8.86$ & 4.76 & $3.64-6.21$ & 10.58 & $6.51-17.20$ \\
\hline $23 \mathrm{~F}$ & 2.63 & $1.86-3.70$ & 4.04 & $2.78-5.87$ & 2.11 & $1.60-2.78$ & 7.31 & $4.81-11.12$ \\
\hline
\end{tabular}

GMC: geometric mean concentration

$10 \%$ in control), 14 (25\% and $15 \%), 19 \mathrm{~F}(25 \%$ and $35.0 \%)$ and 23F (5\% in both) (Figure 1). OPA titers before vaccination were similar for both groups and percent positive individuals was highest for serotypes 14 and 19F (Figure 1).

One month after immunization, a significant increase $(p<0.05)$ in the OPA titer was detected in both groups, with the exception of serotype 14 in individuals receiving PCV7-TT. Nevertheless, the percent of individuals with OPA titers $\geq 1.8$ against this serotype increased from $25 \%$ before vaccination to $65 \% 30$ days after. Post vaccination, over $50 \%$ of volunteers in both groups reached OPA titers $\geq 1.8$ for each serotype analyzed (Figure 1).

Figure 1: Percent of subjects with opsonophagocytic titers $\geq 1: 8$ prevaccination and 30 days post vaccination

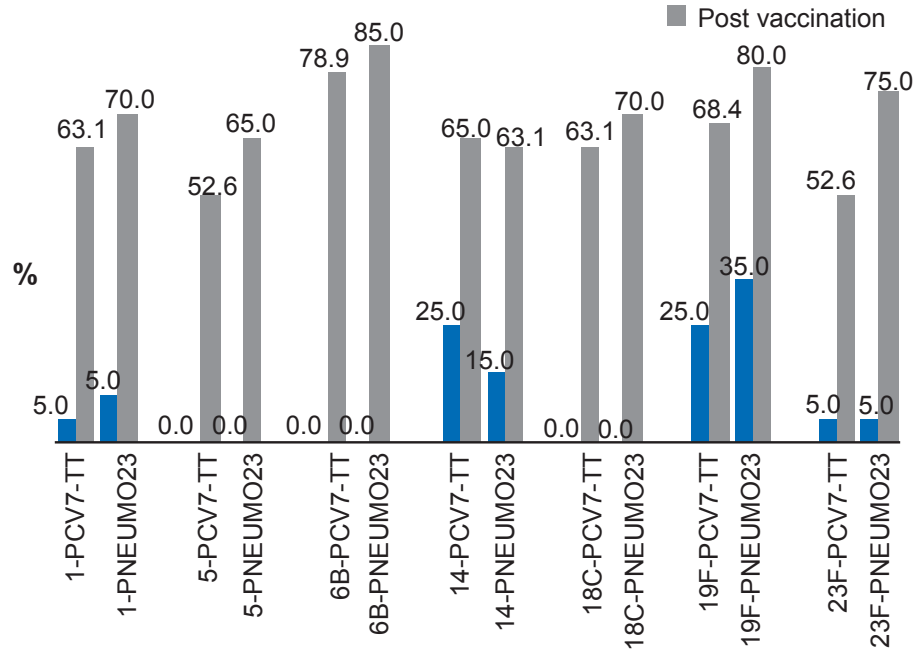

\section{DISCUSSION}

This is the first clinical study evaluating the safety of PCV7-TT, the Cuban heptavalent vaccine candidate against pneumococcus, in healthy adults. We identified some adverse events after vaccination that appeared to be related to vaccination with PCV7TT. Considering that such events appeared in the first 72 hours post inoculation, in future studies, close monitoring of vaccinated subjects is important during this period.

Vaccine-related local and systemic adverse events were mostly mild although some events with moderate intensity occurred and were similar in individuals inoculated with both vaccines. A unique severe adverse event occurred in one individual in the control group, an episode of acute appendicitis that was not considered related to vaccination.

All local adverse events were similar in the two study groups; in general, both products were well tolerated by healthy adult volunteers. These results concur with those obtained with other conjugate vaccines available worldwide, such as Prevnar 7, Prevnar 13 and Synflorix. $[22,23,25,29]$ Furthermore, they warrant further clinical development of the Cuban product and further study of the performance of PCV7-TT in trials involving larger groups.

The main study objective was to demonstrate the safety of the vaccine candidate in adults before using it in a pediatric population, and this was accomplished. Thus, the safety profile resulting from this research provides the basis for additional studies of its use in the pediatric population.

The study has some limitations in comparing immunogenicity of the two vaccines because of different mechanisms of action.

Prevaccination antibody measurements in the 40 participants, enabled characterization of basal levels of antipneumococcal antibodies in Cuban adults. The finding of prevaccination OPAs against serotypes 14 and $19 \mathrm{~F}$ in $15 \%-25 \%$ and $25 \%-35 \%$ of individuals tested in each group, are consistent with previous studies of pneumococcus circulation in Cuba.[13,14]

Several international groups have also reported the presence of basal levels of antipneumococcal antibodies detected by ELISA $\geq 0.20 \mu \mathrm{g} / \mathrm{mL}$ in the general unvaccinated population. Such levels of antibodies against some serotypes might be due to unidentified past infections, to asymptomatic infections, or to presence or asymptomatic carriers in the groups studied.[29]

Both vaccines used for our study were immunogenic and able to induce statistically significant increases in concentration of IgG antibodies against the antigens present in the vaccines. An increase in the OPA titer was also detected.

Even though WHO does not yet recognize the value of OPAs in protecting adult populations, the OPA titer might currently be an appropriate variable for this type of study, better than concentration of capsular polysaccharide lgG. The conjugate vaccine Prevnar-13 was recently authorized for use in adults after demonstrating that the OPA titers they elicit were not inferior to those obtained with PNEUMO-23. [30,31]

The control vaccine's formulation includes $25 \mu \mathrm{g}$ of each capsular polysaccharide, whereas PCV7-TT includes only $2 \mu \mathrm{g}$ of each serotype (except for 6B, which contains $4 \mu \mathrm{g}$, conjugated to TT). Our results demonstrate that PCV7-TT is able to induce serotypespecific immune response against bacterial capsular polysaccharides following antigen presentation to the immune system in the form of glycoconjugate. Comparing this immunogenicity trial with 
other studies using different vaccines and formulations, it is evident that conjugate vaccines are immunogenic in healthy adults. [23,29]

\section{CONCLUSIONS}

In healthy adults, one dose of PCV7-TT, a heptavalent conjugate vaccine candidate against pneumococcus, is safe. Preliminary evaluation of its immunogenicity demonstrates that PCV7-TT is able to activate an immune response against the antigens present in the vaccine. These results open the way to new clinical trials in infants and children; and although PCV7TT is designed for a pediatric population, the current study could also be used as groundwork for designing further studies to protect adult populations as well. -1 -

\section{REFERENCES}

1. Ampofo K, Pavia AT, Stockmann CR, Blaschke AJ, Weng HY, Korgenski KE, et al. Evolution of the epidemiology of pneumococcal disease among Utah children through the vaccine era. Pediatr Infect Dis J. 2011 Dec;30(12):1100-3.

2. Verma R, Khanna P. Pneumococcal conjugate vaccine: A newer vaccine available in India. Hum Vaccin Immunother. 2012 Sep;8(9):1317-20.

3. Hausdorff WP, Feikin DR, Klugman KP. Epidemiological differences among pneumococcal serotypes. Lancet Infect Dis. 2005 Feb;5(2):83-93.

4. Welte T. How can we reduce the mortality of invasive pneumococcal disease? Eur Respir Rev. 2012 Mar 1;21(123):6-7.

5. Fitzwater SP, Chandran A, Santosham M, Johnson $\mathrm{HL}$. The worldwide impact of the sevenvalent pneumococcal conjugate vaccine. Pediatr Infect Dis J. 2012 May;31(5):501-8.

6. Mongardon N, Max A, Bouglé A, Pène F, Lemiale $\mathrm{V}$, Charpentier J, et al. Epidemiology and outcome of severe pneumococcal pneumonia admitted to intensive care unit: a multicenter study. Crit Care. 2012 Aug 15;16(4):R155

7. Tan TQ. Pediatric invasive pneumococcal disease in the United States in the era of pneumococcal conjugate vaccines. Clin Microbiol Rev. 2012 Jul;25(3):409-19.

8. Menon VJ, Corscadden KJ, Fuery A, Thorn-ton RB, Kirkham LA, Richmond PC, et al. Children with otitis media mount a pneumococcal serotype specific serum IgG and IgA response comparable to healthy controls after pneumococcal conjugate vaccination. Vaccine. 2012 Apr 26;30(20):313644.

9. Grabenstein JD, Klugman KP. A century of pneumococcal vaccination research in humans. Clin Microbiol Infect. 2012 Oct;18 Suppl 5:15-24.

10. Johnson HL, Deloria-Knoll M, Levine OS, Stoszek SK, Freimanis Hance L, Reithinger R, et al. Systematic evaluation of serotypes causing invasive pneumococcal disease among children under five: the pneumococcal global serotype project. PLoS Med. 2010 Oct 5;7(10). DOI: 10.1371/journal.pmed.1000348.

11. World Health Organization. Part I: Target Product Profile (TPP) for the Advance Market Commitment (AMC) for pneumococcal conjugate vaccines, Master Table [Internet]. Geneva: World Health Organization; 2008 Feb 22 [cited 2011 Sep 27]. Available from: http://www.who.int/ immunization/sage/target_product_profile.pdf

12. Castaneda E, Agudelo Cl, Regueira M, Corso A, Brandileone MC, Brandão AP, et al. Laboratorybased surveillance of Streptococcus pneumoniae invasive disease in children in 10 Latin American countries: a SIREVA II project, 2000-2005. Pediatr Infect Dis J. 2009 Sep;28(9):e265-70.

13. Toraño Peraza GT, Llanes Caballero R, Pías Solís LM, Abreu Capote M, Valcárcel Sánchez M. Serotipos de Streptococcus pneumoniae en Cuba y progresión de la resistencia a la penicilina. Rev Cubana Med Trop. 2010 MayAug;2(62):157-60. Spanish.

14. Rodríguez M, Pérez A, Dickinson F, Toraño G, Toledo I, Feliciano O, et al. Meningitis bacteriana en Cuba, enero-junio de 2009-2010. Boletín IPK. 2010 Oct 2;20(39):305-12. Spanish.
15. Center for Disease Control and Prevention (CDC). Licensure of 13-valent pneumococcal conjugate vaccine for adults aged 50 years and older. MMWR Morb Mortal Wkly Rep. 2012 Jun 1;61(21):394-5.

16. Pan American Health Organization. Informe Regional de SIREVA II, 2009: Datos por país y por grupos de edad sobre las características de los aislamientos de Streptococcus pneumoniae, Haemophilus influenzae y Neisseria meningitidis, en procesos invasores [Internet]. Washington, D.C.: Pan American Health Organization; 2010 [cited 2014 Jan 11]. 306 p. Available from: http://new.paho.org/hq/dmdocuments/2010/ SIRVA\%20II\%202009.pdf. Spanish.

17. Pan American Health Organization. Informe Regional de SIREVA II, 2010: datos por país y por grupos de edad sobre las características de los aislamientos de Streptococcus pneumoniae, Haemophilus influenzae y Neisseria meningitidis, en procesos invasores [Internet]. Washington, D.C.: Pan American Health Organization 2011 [cited 2014 Jan 11]. 315 p. Available from: http://www.paho.org/hq/index.php?option=com _docman\&task=doc_download\&gid=14772\&lte mid=\&lang=es. Spanish.

18. Viada González CE, Ballagas Flores C, Blanco López Y. Ética en la investigación con poblaciones especiales. Rev Cubana Invest Biomed. 2001 Apr-Jun;20(2):140-9. Spanish.

19. World Medical Association. Declaration of Helsinki. Ethical principles for medical research involving human subjects [Internet]. Ferney-Voltaire (FR): World Medical Association; 2008 Oct [cited 2011 Jan 15]. 5 p. Available from: http://www .wma.net/en/30publications/10policies/b3/17c .pdf

20. National Drugs Quality Control Center (CU) Buenas Prácticas Clínicas en Cuba [Internet] Havana: Ministry of Public Health (CU); 2000 [cited 2014 Dec 12]. 48 p. Available from: http:// www.cecmed.cu/sites/default/files/adjuntos/ Reglamentacion/Dir_BPC.pdf. Spanish.

21. Scott DA, Komjathy SF, Hu BT, Baker S, Supan LA, Monahan CA, et al. Phase 1 trial of a 13-valent pneumococcal conjugate vaccine in healthy adults. Vaccine. 2007 Aug 14;25(33):6164-6.

22. Scott D, Ruckle J, Dar M, Baker S, Kondoh H, Lockhart S. Phase 1 trial of 13-valent pneumococcal conjugate vaccine in Japanese adults. Pediatr Int. 2008 Jun;50(3):295-9.

23. Oosterhuis-Kafeja F, Beutels $P$, Van Damme P. Immunogenicity, efficacy, safety and effectiveness of pneumococcal conjugate vaccines (1998-2006). Vaccine. 2007 Mar 8;25(12):2194212

24. Black S, Shinefield H, Fireman B, Lewis E, Ray P, Hansen JR, et al. Efficacy, safety and immunogenicity of heptavalent pneumococcal conjugate vaccine in children. Northern California Kaiser Permanente Vaccine Study Center Group. Pediatr Infect Dis J. 2000 Mar;19(3):187-95

25. Peña MA, Valera R, Mirabal M, Rodríguez $M$ Armesto $\mathrm{M}$, Menéndez $\mathrm{J}$, et al. Propuesta de un algoritmo para evaluar la causalidad de eventos adversos en los ensayos clínicos de vacunas. Vaccimonitor [Internet]. 2008 Sep-
Dec [cited 2014 Feb 5]:17(3):21-6. Available from: http://scielo.sld.cu/scielo.php?pid=S1025 $-028 X 2008000300004 \&$ script=sci arttext. Spanish.

26. National Drugs Quality Control Center (CU) Requerimientos para la notificación y el reporte de eventos adversos graves e inesperados en los ensayos clínicos autorizados. Havana: Ministry of Public Health (CU); 2007 [cited 2013 Dec 3]. 18 p. Available from: www.bvv.sld.cu/down load.php?url=regulaciones/124413435046.doc Spanish.

27. Schuerman L, Wysocki J, Tejedor JC, Knuf M, $\mathrm{Kim} \mathrm{KH}$, Poolman J. Prediction of pneumococca conjugate vaccine effectiveness against invasive pneumococcal disease using opsonophagocytic activity and antibody concentrations determined by enzyme-linked immunosorbent assay with 22F adsorption. Clin Vaccine Immunol. 2011 Dec;18(12):2161-7.

28. World Health Organization. Training manual for enzyme linked immunosorbent assay for the quantitation of Streptococcus pneumoniae serotype specific IgG (Pn PS ELISA) [Internet]. Geneva: World Health Organization; 2002 Nov [cited 2013 Dec 26]. 29 p. Available from: http://www vaccine.uab.edu/ELISA\%20protocol.pdf

29. Jackson LA, Gurtman A, van Cleeff M, Jansen $\mathrm{KU}$, Jayawardene D, Devlin C, et al. Immunogenicity and safety of a 13-valent pneumococcal conjugate vaccine compared to a 23-valent pneumococcal polysaccharide vaccine in pneumococcal vaccine-naive adults. Vaccine. 2013 Aug 2;31(35):3577-84.

30. Spijkerman J, Veenhoven RH, Wijmenga-Monsuur AJ, Elberse KE, van Gageldonk PG, Knol MJ, et al. Immunogenicity of 13-valent pneumococcal conjugate vaccine administered according to 4 different primary immunization schedules in infants: a randomized clinical trial. JAMA. 2013 Sep 4;310(9):930-7.

31. Lee LH, Frasch CE, Falk LA, Klein DL, Deal CD. Correlates of immunity for pneumococcal conjugate vaccines. Vaccine. 2003 May 16;21(1718):2190-6

\section{THE AUTHORS}

Nadezhda González García (Corresponding author: ngonzalez@finlay.edu.cu), physician with dual specialties in family medicine and microbiology, and master's degree in virology, CQB, Havana, Cuba

Beatriz Paredes Moreno, pharmacist. Researcher, Biomolecular Chemistry Center (CQB), Havana, Cuba.

Sonia Pérez Rodríguez, internist, National Toxicology Center (CENATOX), Havana, Cuba.

Mayelín Mirabal Sosa, mathematician with master's degree in statistics and probability. Biostatistician, Finlay Institute, Havana, Cuba. 
Ivonne Rivero Vázquez, nurse, CENATOX, Havana, Cuba.

Carlos A. González Delgado, physician specializing in pharmacology, with master's degree in experimental toxicology, CENATOX, Havana, Cuba.

Alina Díaz Machado, physician specializing in pharmacology, CENATOX, Havana, Cuba.

Dagmar García Rivera, pharmacist. Director of research and development, CQB, Havana. Cuba.

Laura Rodríguez Noda, microbiologist. Researcher, CQB, Havana, Cuba.
Amarilis Pérez Baños, pharmacist. Researcher, CQB, Havana, Cuba.

Yamilka Soroa Millán, veterinarian, Researcher, CQB, Havana, Cuba.

Darielis Santana Mederos, biochemist. Researcher, CQB, Havana, Cuba.

Alina Álvarez León, physician with dual specialties in family medicine and immunology, CQB. Havana, Cuba.

Yury Valdés Balbín, chemist. Project director and deputy director, CQB, Havana, Cuba.
Vicente Vérez Bencomo, chemist. Director general, CQB, Havana, Cuba.

Nadezhda González, Beatriz Paredes and Sonia Pérez contributed equally to this article.

Submitted: April 21, 2014

Approved for publication: October 10, 2015 Disclosures: Authors NGG, BPM, DGR, LRN, $A P B, Y S M, D S M, A A L, Y V B$, and $V V B$ are employees of the CQB, where PCV7-TT was developed and produced.

\title{
$7^{\text {th }}$ Intercontinental Convention on Psychology
}

\author{
May 9-13, 2016 \\ Havana's International Convention Center
}

Topics:

- Human development and subjectivity

- Identity and diversity: society, groups, families, gender, generations

- Applied psychologies: addictions, health, education, culture, sports, communities, organizations, communications, social institutions, disasters

- Psychological theory and its relation to other sciences

- Psychology: training and practice

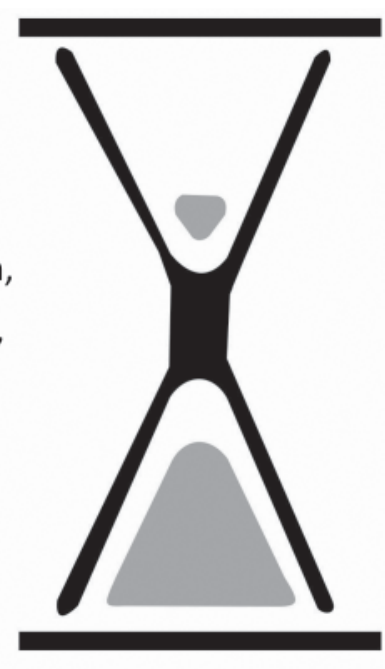

Languages: English, Spanish

Partial List of Sponsors: Cuba's Ministries of Higher Education, Public Health, Education, and Culture; University of Havana's Centers for Psychology and Sociology Research and for Demographic Studies; American Association of Psychology; American Association for Psychology Training and Teaching; Coalition for Practice Research (USA); UNESCO-Cuba; UNICEF-Cuba; Latin American Network of Emergency and Disaster Psychology; Autonomous University of Madrid School of Psychology

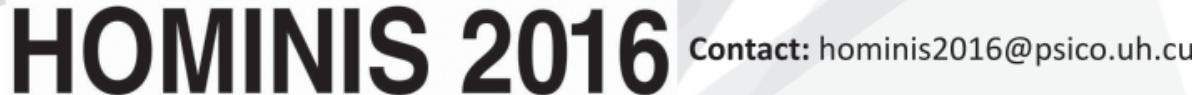

